\title{
Educational intervention for promoting stretching exercise behavior among a sample of Iranian office employees: applying the Health Promotion Model
}

This article was published in the following Dove Medical Press journal:

Journal of Pain Research

\author{
Mohammad Hossein \\ Delshad' \\ Sedigheh Sadat Tavafian' \\ Anoshirvan Kazemnejad ${ }^{2}$ \\ 'Department of Health Education \\ and Health Promotion, Faculty of \\ Medical Sciences, Tarbiat Modares \\ University, Tehran, Iran; ${ }^{2}$ Department \\ of Biostatistics, Faculty of Medical \\ Sciences, Tarbiat Modares University, \\ Tehran, Iran
}

Introduction: Health Promotion Model (HPM) is one comprehensive model by which health behavior predicting factors could be determined.

Purpose: This study aimed to investigate the effects of a designed interventional program based on HPM on promoting stretching exercise (SE) behavior among office employees.

Patients and methods: This interventional designed study was carried out on 87 office employees who were working in the three health networks affiliated to Shahid Beheshti University of Medical Sciences in Tehran, Iran. These participants were randomly divided into intervention group ( $\mathrm{N}=44)$ who complied with educational program based on HPM and control group ( $\mathrm{N}=43$ ) who did not receive the program. The data were collected through a demographic questionnaire and a researcher-made questionnaire based on HPM at three times of baseline, 3- and 6-month follow-ups and analyzed using SPSS version 19.

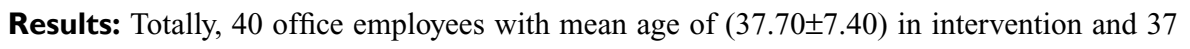
ones with mean age of (35.97 \pm 7.34$)$ in control group were assessed. At baseline, both groups were the same regarding the HPM constructs of perceived barriers, perceived self-efficacy, commitment to plan, and interpersonal influences $(P>0.05)$. However, following intervention, there was a significant difference between two groups during 6-month follow-up in all these predictor factors $(P<0.0001)$. Furthermore, the mean score of $\mathrm{SE}$ behavior in intervention

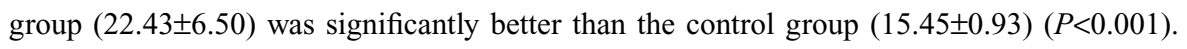

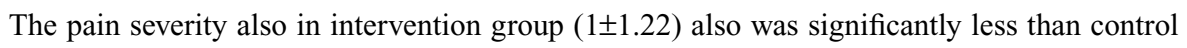
group (2 \pm 2.03$)$ after 6-month follow-up $(P<0.001)$.

Conclusion: The SE educational programs applied in this study were effective for promoting SE among office employees.

Keywords: educational intervention, stretching exercises, Health Promotion Model, office employees

\section{Introduction}

Globally, more than half of world's population are directly or indirectly involved with biopsychosocial factors of workplace and spent most of their waking hours in their workplace. It has been argued that the workplace characteristics have great potential influence on wellness of workers and also their families indirectly. ${ }^{1}$ One of the most important risk factors for office workers is sitting position for most of the working hours in their office. ${ }^{2}$ Furthermore, working with computer in a sedentary posture without performing stretching exercise (SE) is another increasing risk factor. ${ }^{2}$ Lack of
Correspondence: Sedigheh Sadat Tavafian Department of Health Education and Health Promotion, Faculty of Medical Sciences, Tarbiat Modares University, PO Box I4I I5-III, Tehran, Iran Tel +98 2I 2884547

Fax +982182884555

Email Tavafian@modares.ac.ir 
enough time and facilities for performing physical activity - during working time - is another main problem of office employees which may lead to many health problems, for instance musculoskeletal disorders (MSDs). ${ }^{3}$

Most office employers spend hours in a seated position in front of a computer screen. Repetitive activities, such as typing for long periods of time, may negatively impact posture and mobility, potentially leading to pain. One approach for improving back health and reducing the discomfort associated with repetitive workplace activities is to promote mobility, ${ }^{4}$ muscular balance, and strength for optimal movement, posture, and wellness. The exercises with the use of the educational model can be easily incorporated into your workday. ${ }^{5,6}$ Previous evidence showed that SE plays an important role in decreasing MSD pain as well as improving pain. ${ }^{7}$

Therefore, physical fitness program in workplaces may be broadly beneficial such as reducing pain, disability, and absenteeism subsequently to employers. ${ }^{1}$ They are a constellation of painful disorders of muscles, tendons, joints, and nerves, which can affect all body parts, although the neck, upper limb, and back are the most common areas. Most studies have highlighted the advantageous of SE to decrease pain and promote flexibility and function of different parts of body such as neck, upper limb, and back which are the most common area. ${ }^{3}$ However, there are no definite conclusions about types of exercise for relief of pain and improving muscle functions for office workers. ${ }^{8}$

Workplace-based interventions are beneficial for reducing MSD costs through promoting education, knowledge, and health experiences. ${ }^{9}$ It has been discussed if incorrect postures among office workers became a habit due to lack of health care education and lack of exercise, it would be difficult for office employees to change the habits. ${ }^{2} \mathrm{SE}$ is defined as physical activity that is planned, structured, and repetitive, with a final or intermediate objective to improve or maintain physical fitness. ${ }^{10}$ Performing more than ten stretching or strengthening exercises of particular body activities per day is the best strategy for decreasing the risk of aggravation of painful MSD among office employees. ${ }^{8}$ Office employees can select from a range of times for both sitting (5-120 minutes) and break (1-60 minutes) periods. When a break is due, office employees are prompted to perform stretching or strengthening exercises of a particular body part preselected. ${ }^{7}$

Health Promotion Model (HPM) is one comprehensive model by which health-behavior predicting factors like perceived barrier/benefit/self-efficacy and others are determined and could be implied in worksites. ${ }^{11}$ Pender et al (2015) believed that worksite health promotion programs could help employees to obtain healthy behavior during their working that leads to lower health care costs and enhanced productivity. The HPM is an attempt to depict the multidimensional nature of persons interacting with their interpersonal and physical environments regarding health. Research has substantiated that HPM is a motivational model for understanding the major determinants of health behaviors. ${ }^{11}$ Perceived barriers to action, perceived self-efficacy, commitment to plan of action, and interpersonal influences were significant predictors for SE behavior.

Therefore, this study aimed to investigate the effects of a designed interventional program based on HPM on performing SE and reducing musculoskeletal pain among office employees. The hypothesis was that the program would be effective to increase SE through improving HPM-based predictors and decrease MSDs among office employees.

\section{Patients and methods Study population}

This interventional designed study was carried out on 87 office employees who were working in two health networks affiliated to Shahid Beheshti University of Medical Sciences (SBUMS) in Tehran, Iran, from September 2016 to February 2018. The sample size was calculated based on the following formula (Figure 1), in which the parameters from previous document $^{12}$ that has been conducted in Iran, were used.

Based on this formula, 23 subjects in each group were confirmed. However, considering sample attrition and increasing the power of the study, 40 participants were considered for each group. To select the participants, multistage sampling was applied by which in the first stage three health networks were selected randomly and in the next stage, two health networks

$$
\begin{aligned}
& N=\frac{\left(z_{1-\alpha / 2}+z_{1-\beta}\right)^{2}\left(s_{1}^{2}+s_{2}^{2}\right)^{2}}{\left(\mu_{1}-\mu_{2}\right)^{2}} \\
& n=\frac{\left(s_{1}^{2}+s^{2}{ }_{2}\right)}{\left(\mu_{1}-\mu_{2}\right)^{2}} f(\alpha, \beta)=\frac{\left(3.06^{2}+4.53^{2}\right)}{(16.81)^{2}} \times 12.96=23+40 \%=33
\end{aligned}
$$

Figure I Sample size formula. 
were selected as intervention (Shemiranat center with 76 employees) or control (east center with 112 employees) group. In the next stage, from intervention center, 44 employees and from control center, 43 employees who were eligible and satis- fied to enter into the study were selected randomly. Finally at 6-month follow-up - because of attrition - 40 employees in intervention and 37 employees in control group were assessed. Figure 2 shows the complete procedure of sampling.

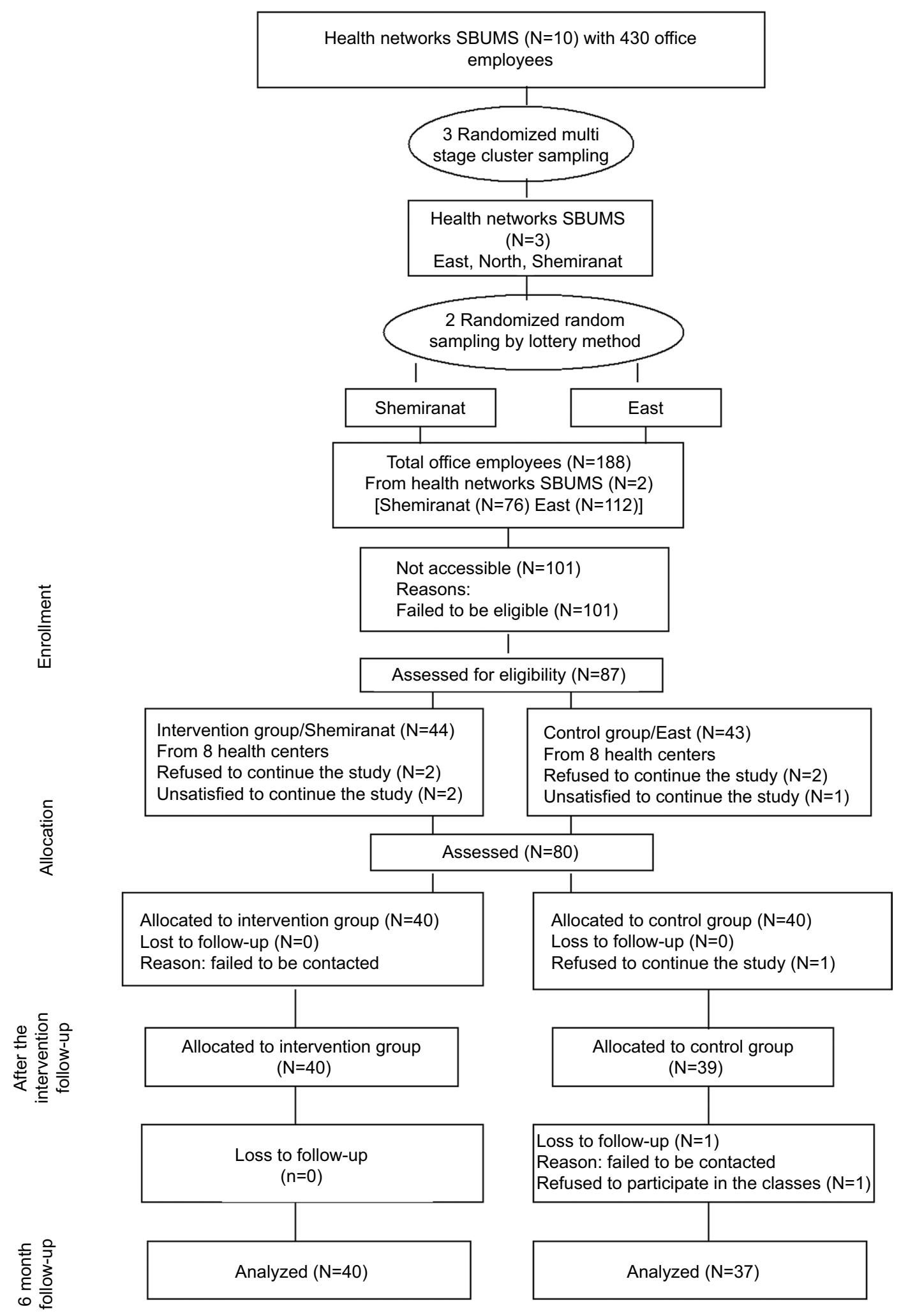

Figure 2 Flowchart of health centers and office employees' recruitment, randomization, and follow-up. 
Inclusion criteria were as follows: working in the SBUMS as employee, working with computer more than 4 hours/day as his/her job, and being satisfied to be studied. Excluding criteria were as suffering from any disability or illness that prevents them from doing SEs, being not allowed to do SE because of their physicians' recommendation and not being able to participate in the educational classes.

\section{Interventional program}

First, the interventional program was designed based on previous studies. ${ }^{13,14}$ This interventional program was accomplished in two sessions. The first session took 120 minutes. In this session, the participants were familiar with their musculoskeletal system, the right postures of this system and occupational factors which may cause skeletal pain and complications. Furthermore, in this session, the benefits of SE to improve musculoskeletal pain were discussed. In this session, the educational content was presented through lecture, slide shows, and role playing. The second session took 120 minutes and divided into two 60-minute section. In first section, the participants discussed about the factors influencing doing SE like the ways to decrease perceived barriers and improve perceived self-efficacy to do SE.

Furthermore, in this section, the approaches to improving commitment to plan of doing SE and improving interpersonal influences to do this behavior were discussed. In the second 60-minute section, the skills of doing SE behaviors for different muscles were practiced with the participants. In all sessions, six to eight office employees took part. At the end of the two sessions, the participants were provided with a CD included the whole educational program. Moreover, as a reminder, an autoregressive software application was installed in all participants' computers that included all information on how to handle proper SE during working with computer. Furthermore, Learning Management System was set by the first author to remind all educated program.

The intervention group was recommended to perform neck, waist, and shoulder SEs about 10-30 minutes/day, 2-5 days/week during up to 10 weeks. The SE program included one to five repetitions of neck stretching, shoulder stretching, and back SE. Performing each stretching/strength exercise at the ultimate joint motion took 10-30 seconds and was repeated two to three times per muscle on average. ${ }^{15}$

\section{Data collection}

The first author collected the data through three questionnaires including demographic questionnaire, Stretching Exercise Predicting Scale (SEPS), and Visual Analog Scale (VAS).
All the questionnaires were completed by the participants of both groups; at the same time, SEPS was completed at the beginning of the study, 3-month, and 6-month follow-ups. SE behavior scale and VAS were completed at the beginning of the study and 6-month follow-up.

The demographic questionnaire included 19 questions regarding age, educational level, gender, suffering from musculoskeletal pain, socioeconomic status, marriage status, employment status, duration of pain, duration of treatment, type of employment, and other variables that are shown in Table 1.

The second questionnaire was about the subscales of SEPS $^{13}$ and included constructs as perceived barriers to action, perceived self-efficacy, commitment to plan of action, and interpersonal influences. This scale included 29 items with 4-option Likert system from never to always scored 1-4 and the high scores indicated better situation expect for perceived barriers to action that the higher score indicated worse situation.

The second section of SEPS was regarding SE behavior that was assessed using just one question. An answer for this question was evaluated by a 2 -option scale with a range of $1-2$.

The SE behavior checklist also was used in this study. This checklist included 10 items. These items were focused on the SEs for the neck, waist, shoulder and back muscles throughout the working day. This checklist was measured on a 3-point Likert scale for each item which was measured from 1 to 3 and for the total of the items was from 10 to 30 that the lower score was worse behavior. The SEPS was validated in previous study. ${ }^{14}$ This check list was completed by the participants.

The fourth tool was VAS for measuring musculoskeletal pain. VAS is a one-dimensional scale to measure pain severity. The office employees were asked to select a number which showed their pain severity. In this scale, number 10 means severe pain and number 0 means no pain. The validity and reliability of VAS were reported in Breivik et al. ${ }^{16}$ Translation of this scale into Persian language is available and its validity/ reliability was well documented. ${ }^{17,18}$

\section{Statistical analysis}

The data were entered into the SPSS, version 16 (IBM Corporation, Armonk, NY, USA). All the data analyses were conducted according to the pre-established analysis plan. Proportions were compared by using the chi-squared test. Mean scores were analyzed through the repeated measures and independent/dependent $t$-test. The comparison of the two groups was done at the beginning of the study, 3-month, and 
Table I Demographic characteristics of the studied office employees of both groups at the beginning of the study

\begin{tabular}{|c|c|c|c|}
\hline \multirow{2}{*}{$\begin{array}{l}\text { Group variable } \\
\text { number }\end{array}$} & \multirow{2}{*}{\begin{tabular}{|l} 
Intervention $(\mathbf{N}=40)$ \\
$\mathbf{N}(\%)$
\end{tabular}} & \multirow{2}{*}{$\begin{array}{l}\text { Control }(\mathrm{N}=37) \\
\mathbf{N}(\%)\end{array}$} & \multirow[t]{2}{*}{$P$-value ${ }^{a}$} \\
\hline & & & \\
\hline \multicolumn{3}{|l|}{ Age (years) } & \multirow[t]{6}{*}{0.80} \\
\hline$\leq 25$ & - & $2(5.4 I)$ & \\
\hline $26-30$ & $4(10)$ & $7(|8.9|)$ & \\
\hline $3 I-35$ & $10(25)$ & $8(21.62)$ & \\
\hline $36-40$ & $16(40)$ & $10(27.03)$ & \\
\hline $41.00+$ & $10(25)$ & $10(27.03)$ & \\
\hline \multicolumn{3}{|c|}{ Body mass index (BMI) } & \multirow[t]{5}{*}{0.13} \\
\hline Under 20 & $2(5)$ & $2(5.4 I)$ & \\
\hline $20-25$ & $25(62.5)$ & $15(40.54)$ & \\
\hline $25-30$ & II (27.5) & $17(45.94)$ & \\
\hline Above 30 & $2(5)$ & $3(8.11)$ & \\
\hline \multicolumn{3}{|l|}{ Educational level } & \multirow[t]{6}{*}{0.35} \\
\hline Diploma & $\mathrm{I}(2.5)$ & - & \\
\hline Associate degree & $4(10)$ & $5(13.52)$ & \\
\hline Undergraduate & $12(30)$ & $15(40.54)$ & \\
\hline Masters & $13(32.5)$ & $7(|8.9|)$ & \\
\hline Doctorate & $10(25)$ & $10(27.03)$ & \\
\hline \multicolumn{3}{|l|}{ Gender } & \multirow[t]{3}{*}{0.47} \\
\hline Male & $8(20)$ & $10(27.1)$ & \\
\hline Female & $32(80)$ & $27(72.9)$ & \\
\hline \multicolumn{3}{|c|}{ Suffering from musculoskeletal pain } & \multirow[t]{3}{*}{0.27} \\
\hline Yes & 27 (67.5) & $25(67.5)$ & \\
\hline No & $13(32.5)$ & $12(32.5)$ & \\
\hline \multicolumn{3}{|l|}{ Economic status } & \multirow[t]{4}{*}{0.63} \\
\hline Poor & $3(7.5)$ & $3(8.1)$ & \\
\hline Average & $21(52.5)$ & $22(59.5)$ & \\
\hline Good & $16(40)$ & $12(32.4)$ & \\
\hline \multicolumn{3}{|l|}{ Marriage status } & \multirow[t]{3}{*}{0.57} \\
\hline Single & $23(57)$ & $10(27.1)$ & \\
\hline Married & $17(43)$ & $27(72.9)$ & \\
\hline \multicolumn{3}{|c|}{ Employment status } & \multirow[t]{3}{*}{0.20} \\
\hline Formal & $12(30)$ & $14(37.8)$ & \\
\hline Informal & $28(70)$ & $23(62.2)$ & \\
\hline Under-treatmen & & & 0.27 \\
\hline Yes & $27(67.5)$ & $25(67.6)$ & \\
\hline No & $13(32.5)$ & $12(32.4)$ & \\
\hline Duration of musc & s)/duration of treatme & & 0.63 \\
\hline$<1$ & $17(77.3)$ & $17(85)$ & \\
\hline $1-3$ & $2(9.1)$ & I (5) & \\
\hline $3-5$ & $2(9.1)$ & I (5) & \\
\hline $5+$ & $\mathrm{I}(4.5)$ & $I(5)$ & \\
\hline Early withdrawal & atment (n) & & 0.22 \\
\hline$<1$ & - & - & \\
\hline $1-3$ & I (20) & $4(80)$ & \\
\hline $3-5$ & $I(20)$ & I (20) & \\
\hline $5+$ & $3(60)$ & - & \\
\hline Type of pain & & & 0.45 \\
\hline Work related & $10(37.1)$ & $8(32)$ & \\
\hline Non-work related & $17(62.9)$ & $17(68)$ & \\
\hline Residency & & & 0.13 \\
\hline City & $38(95)$ & $36(97.3)$ & \\
\hline Village & $2(5)$ & I (2.7) & \\
\hline
\end{tabular}

Notes: ${ }^{2}$ Chi-squared tests. In general, office employees who had pain for more than a year, they have given up treatment during the pain, that is, under the supervision of their physician. 
6-month follow-ups. Furthermore, repeated measure ANOVA was applied to compare two groups 6 months.

\section{Ethics statement}

All ethical issues were considered in this study. The research procedures were completely explained for the potential participants. To ensure confidentiality, office employees were asked not to provide their names in the questionnaires. All office employees voluntarily signed the consent form to be studied. Ethics committee of Tarbiat Modares University (TMU) approved the study through the code IR.TMU. REC.1395.329. The Iranian Randomized Clinical trials registration at http://www.irct.ir/ web page address approved the study through the ID number IRCT2016082429512N1. This study was conducted in accordance with the Declaration of Helsinki. The authors of the present study do not intend to share individual de-identified participant data.

\section{Results}

A total of 77 eligible office employees completed the study. The mean ages of control $(\mathrm{N}=40)$ and intervention group $(\mathrm{N}=37)$ were $35.97 \pm 7.34$ and $37.70 \pm 7.40$, respectively. Table 1 shows the comparison of sociodemographic char- acteristics of the studied participants between both groups at the beginning of the study. According to this table, there were no significant differences between the two groups $(P>0.05)$.

The mean scores of predictive constructs based on SEPS of the two studied groups at three time points are shown in Table 3. As this table shows, the mean scores of the predictive constructs of both groups were the same at the beginning of the study $(P>0.05)$. However, the independent $t$-test showed these scores were improved in intervention group after educational intervention $(P<0.001)$. The results from repeated measure ANOVA at the baseline, 3-month, and 6-month follow-ups are shown in Table 2. According to this table, there were significant differences in scores of predictive constructs within each group by time $(P<0.001)$. Furthermore, each group was signifcantly different in different time $(P<0.001)$ and the interaction between time and group was also different signifcant $(P<0.001$; Table 2$)$.

Differences in SE behavior between the two groups were also examined in this study.

Table 3 shows statistically significant difference between the two groups in terms of the frequency rate of employees who did SE at the beginning of the study and 6-month follow-

Table 2 Comparison of both groups over time in terms of predictors of SE and the SE behavior

\begin{tabular}{|c|c|c|c|c|c|c|}
\hline \multirow[t]{2}{*}{ Variables } & \multirow[t]{2}{*}{ Time follow-up } & \multirow{2}{*}{$\begin{array}{l}\text { Intervention } \\
(\mathrm{N}=40) \\
\text { Mean } \pm \mathrm{SD}\end{array}$} & \multirow{2}{*}{$\begin{array}{l}\text { Control } \\
(\mathrm{N}=37) \\
\text { Mean } \pm \text { SD }\end{array}$} & \multicolumn{3}{|l|}{$P$-value ${ }^{a}$} \\
\hline & & & & $\begin{array}{l}\text { Time } \\
\text { difference }\end{array}$ & $\begin{array}{l}\text { Group } \\
\text { difference }\end{array}$ & $\begin{array}{l}\text { Time and group } \\
\text { interaction }\end{array}$ \\
\hline \multirow{3}{*}{$\begin{array}{l}\text { Perceived } \\
\text { barriers to } \\
\text { action }\end{array}$} & Baseline & $25.52 \pm 2.84$ & $25.24 \pm 2.74$ & \multirow[t]{4}{*}{$<0.001$} & \multirow[t]{4}{*}{0.003} & \multirow[t]{4}{*}{$<0.001$} \\
\hline & 3-month follow up & $21.57 \pm 3.34$ & $25.02 \pm 2.89$ & & & \\
\hline & 6-month follow-up & $22.70 \pm 3.31$ & $24.86 \pm 2.99$ & & & \\
\hline$P$-value ${ }^{\mathrm{a}}$ & & $<0.001$ & 0.476 & & & \\
\hline \multirow{3}{*}{$\begin{array}{l}\text { Perceived } \\
\text { self-efficacy }\end{array}$} & Baseline & $14.52 \pm 3.02$ & $14.75 \pm 2.90$ & \multirow[t]{4}{*}{$<0.001$} & \multirow[t]{4}{*}{0.003} & \multirow[t]{4}{*}{$<0.001$} \\
\hline & 3-month follow up & $19.62 \pm 3.7 \mid$ & $14.56 \pm 2.96$ & & & \\
\hline & 6-month follow-up & $16.37 \pm 2.77$ & $15.05 \pm 3.29$ & & & \\
\hline$P$-value ${ }^{\mathrm{a}}$ & & $<0.001$ & 0.447 & & & \\
\hline \multirow{3}{*}{$\begin{array}{l}\text { Commitment } \\
\text { to plan of } \\
\text { action }\end{array}$} & Baseline & $13.82 \pm 2.68$ & $|4.21 \pm 2.3|$ & \multirow[t]{4}{*}{$<0.001$} & \multirow[t]{4}{*}{$<0.001$} & \multirow[t]{4}{*}{$<0.001$} \\
\hline & 3-month follow up & $22.42 \pm 3.34$ & $15.08 \pm 3.04$ & & & \\
\hline & 6-month follow-up & $17.42 \pm 2.13$ & $15.13 \pm 2.90$ & & & \\
\hline$P$-value ${ }^{\mathrm{a}}$ & & $<0.001$ & 0.238 & & & \\
\hline \multirow{3}{*}{$\begin{array}{l}\text { Interpersonal } \\
\text { influences }\end{array}$} & Baseline & $11.85 \pm 4.59$ & $11.65 \pm 3.33$ & \multirow[t]{4}{*}{$<0.001$} & \multirow[t]{4}{*}{$<0.001$} & \multirow[t]{4}{*}{$<0.001$} \\
\hline & 3-month follow up & $15.08 \pm 3.18$ & $11.14 \pm 1.87$ & & & \\
\hline & 6-month follow-up & $13.42 \pm 2.19$ & $12.05 \pm 2.18$ & & & \\
\hline$P$-value ${ }^{\mathrm{b}}$ & & $<0.001$ & $0.44 \mathrm{I}$ & & & \\
\hline \multirow[t]{3}{*}{ SE behavior } & Baseline & $16.66 \pm 2.87$ & $15.80 \pm 1.25$ & \multirow[t]{4}{*}{$<0.001$} & \multirow[t]{4}{*}{$<0.001$} & \multirow[t]{4}{*}{$<0.001$} \\
\hline & 3-month follow up & $20.52 \pm 5.90$ & $16.15 \pm 1.34$ & & & \\
\hline & 6-month follow-up & $22.43 \pm 6.50$ & $15.45 \pm 0.93$ & & & \\
\hline$P$-value ${ }^{\mathrm{b}}$ & & $<0.001$ & 0.499 & & & \\
\hline
\end{tabular}

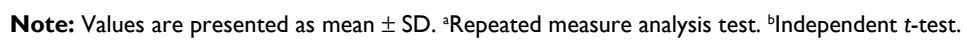

Abbreviation: SE, stretching exercise. 
up $(P<0.001)$. There was significant difference between the two groups at 6-month follow-up in terms of pain severity that was measured through VAS ( $P=0.008$; Table 4$)$. However, the two groups were the same at the beginning of the study in this regard.

\section{Discussion}

The present study showed that the educational intervention based on the predictor constructs of HPM including perceived barriers to action, perceived self-efficacy, commitment to plan of action, and interpersonal influences could significantly improve the SE behavior among office employees at 6-month post intervention. The results of the present study showed that the interventional program could significantly improve predictive constructs in intervention group. Therefore, it might be argued that the SE behavior improvement in intervention group has been due to improvement in these predictive constructs.

However, a previous study indicated that there has been no association of self-reported aerobic physical activity, muscle-strengthening physical activity, and stretching behavior with presenteeism. ${ }^{14}$ Another study that was conducted on the activity patterns among office employees verified the inhibition of the development of targeted worksite activity programming and educational intervention. ${ }^{19}$ The findings of Robertson's study are in line with the present study and indicated that the improved psychosocial factors which are adopted with workstation arrangements and computing postures in the intervention group could happen through an educational program such as a flexible workshop..$^{20}$ Moreover, Hyeonkyeong study showed that a community-based stretching intervention consisting of SE program, individual phone counseling, and short message service could improve $\mathrm{SE}$, increase the participants' flexibility, reduce work-related MSD symptoms, and increase health outcomes among female migrant workers. ${ }^{21}$

These discrepancies between the results of the studies could be due to the different sample sizes, different target groups, and different types of education and training programs. Therefore, these studies have suggested further research on different educational interventions to confirm findings, to investigate mediation effects, and subsequently to develop more effective intervention programs.

The results of the present study showed that following the intervention, the mean score of the perceived self-efficacy among office employees in the intervention group increased significantly. This finding was also consistent with the results of previous studies. ${ }^{22,23}$ Self-efficacy has been considered as a strong predictor of exercise adoption. Given the importance of self-efficacy to the adoption of a correct body posture among office employees, researchers should focus on developing educational interventions aimed at increasing self-efficacy among this target group. ${ }^{22,24}$

Also, the present study found that commitment to a plan of action in the intervention group was considerably increased compared to the control group, 6 months after

Table 3 Comparison of SE behavior rate in both groups at two time points of the study

\begin{tabular}{|c|c|c|c|c|c|c|}
\hline \multicolumn{3}{|c|}{ Group } & \multirow{2}{*}{\begin{tabular}{|l} 
Intervention \\
group $(n=40)$
\end{tabular}} & Control & \multirow[t]{2}{*}{$\chi^{2}$} & \multirow[t]{2}{*}{$P$} \\
\hline & & & & $\mathbf{N}(\%)$ & & \\
\hline \multirow[t]{4}{*}{ SE } & \multirow[t]{2}{*}{ Baseline } & Yes & $12(30)$ & $10(27)$ & \multirow[t]{2}{*}{0.083} & \multirow[t]{2}{*}{0.773} \\
\hline & & No & $28(70)$ & $27(73)$ & & \\
\hline & \multirow{2}{*}{$\begin{array}{l}\text { 6-month follow-up } \\
\text { baseline }\end{array}$} & Yes & $37(92.5)$ & II (29.7) & \multirow[t]{2}{*}{32.25} & \multirow[t]{2}{*}{$<0.001$} \\
\hline & & No & $3(7.5)$ & $26(70.3)$ & & \\
\hline
\end{tabular}

Note: $\mathrm{N}$ indicates number of office workers.

Abbreviation: SE, stretching exercise.

Table 4 Comparison of pain severity between two groups at two time points of the study

\begin{tabular}{|l|l|l|l|}
\hline Group & Before intervention & 6 months after intervention & $\begin{array}{l}\text { P-value } \\
\text { within group }\end{array}$ \\
\cline { 2 - 4 } & Mean \pm SD & Mean \pm SD & 0.008 \\
\hline Intervention group $(\mathrm{n}=40)$ & $2.07 \pm 1.40$ & $\mathrm{I} \pm 1.22$ & 0.23 \\
\hline Control group $(\mathrm{n}=37)$ & $2.1 \pm 2.0 \mathrm{I}$ & $2 \pm 2.03$ & - \\
\hline P-value between groups & 0.28 & $<0.00 \mathrm{I}$ & \\
\hline
\end{tabular}


following the intervention group. Commitment to a plan of action is a key factor to the initiation of a behavioral event or to the changing of unhealthy behavior. ${ }^{11}$ In Gill's study, commitment to carry out a specific action at a given time and place has been verified as the most important structure for behavior change. ${ }^{25}$ Some similar studies of other models, for instance Stenberg et $\mathrm{al}^{26}$ and Roebuck et al, ${ }^{27}$ showed that commitment to a plan of action and the intention to carry out a particular health behavior were the most important factors for health behavior. ${ }^{28}$

Several studies have investigated the effectiveness of different prevention protocols including educational programs and ergonomic changes in work sites, SE and multidisciplinary programs for decreasing MSDs, especially MSDs in office workers and other groups. ${ }^{29-32}$

Previous evidence has revealed that barriers consist of perceptions about the unavailability, inconvenience, expense, difficulty, or time-consuming nature of a SE. ${ }^{11}$ The educational program of the present study could decrease the barriers to action for performing SE. In other words, after the educational intervention, office employers were able to obtain necessary knowledge about perceived barriers to action and how to prevent it in order to perform a SE behavior. This finding of the present study was also consistent with the results of other studies. ${ }^{28,30,31}$ Barriers usually prevent the performance of SE behavior. Usually, few studies have focused on barriers for performing SE behaviors in detail after an intervention. We suggest focusing on these barriers and benefits SE while at work can be implemented to reduce the occurrence of painful disorders among office workers.

The results of this study showed that the intervention improved the interpersonal influences of stretching in the intervention group. The findings were also consistent with the results of Laird et $\mathrm{al}^{33}$ and Keegan et al. ${ }^{34}$ It is a known fact that social norms regulate standards for a particular task, and people accept or reject a behavior based on norms. Thus, changing the social environment norms in favor of stretching is a very effective way of performing and sustaining the habit of regular exercises.

Despite the high prevalence of MSDs among office employees and the importance of SE behavior to reducing the painful disorder of muscles, to the best of our knowledge, few educational interventions have been developed on this issue. The current educational programs regarding this issue are insufficient. Therefore, further theory-based education efforts should be established for office employees and should be taken to increase SE and prevent MSDs in-service training. It is recommended that further similar researches should be designed and conducted for worksite office employees and should involve a longer period of time follow-up. The present study showed that educational intervention based on the predictor factors of HPM could significantly improve pain severity in office employees 6 months after the intervention. In our study, reduced pain severity in more workers in the intervention group was occurred.

This result is in the line of other studies that revealed the education programs based on the HPMs were more effective than waiting list. ${ }^{35,36}$ Furthermore, in consistent with present results, the previous evidence verified that exercise reminder software programs with 10 -week exercises could reduce pain severity among office workers. ${ }^{37}$

\section{Limitations}

Despite strong points of this study such as multicentral sampling and comparing the results with control group, there is few limitation such as self-reporting and small sample size that should be paid attention in future studies. Despite these limitations, the results are consistent with existed valid evidence that showed the effects of education on improving healthy behaviors and reducing pain severity. ${ }^{38}$ However, doing more studies in future is recommended to confirm the results.

\section{Conclusion}

This study revealed that improving self-efficacy, commitment to plan action, and reducing barrier to action among office employees could improve SE behavior in this target group. However, doing more researches to confirm the results is guaranteed.

\section{Acknowledgments}

The authors thank all the study participants. The authors would like to thank the research deputy of Tarbiat Modares University for its financial support of this study. The authors also thank the Shahid Beheshti University of Medical Sciences authorities for their assistance with the study.

\section{Author contributions}

MHD conducted the whole study and had full access to all data for analysis. He confirmed the eligibility of the office workers for the study. He was involved in drafting the article. SST and AK supervised the whole study and approved a final version of the manuscript. All authors contributed toward data analysis, drafting and revising the paper. gave final approval of the version to be published and agree to be accountable for all aspects of the work.

\section{Disclosure}

The authors report no conflicts of interest in this work. 


\section{References}

1. Batt ME. Physical activity interventions in the workplace: the rationale and future direction for workplace wellness. Br J Sports Med. 2009;43(1):47-48.

2. Kim D, Cho M, Park Y, Yang Y. Effect of an exercise program for posture correction on musculoskeletal pain. J Phys Ther Sci. 2015;27(6):1791-1794.

3. Mohammed M, Naji FL. Benefits of exercise training for computerbased staff: a meta analyses. Int J Kinesiol Sports Sci. 2017;5(2):16-23.

4. Shariat A, Cleland JA, Danaee M, Kargarfard M, Sangelaji B, Tamrin SBM. Effects of stretching exercise training and ergonomic modifications on musculoskeletal discomforts of office workers: a randomized controlled trial. Braz J Phys Ther. 2018;22(2):144-153.

5. Patti A, Bianco A, Paoli A, et al. Pain perception and stabilometric parameters in people with chronic low back pain after a Pilates exercise program: a randomized controlled trial. Medicine. 2016;952414(2):e2414.

6. Searle A, Spink M, Ho A, Chuter V. Exercise interventions for the treatment of chronic low back pain: a systematic review and meta-analysis of randomised controlled trials. Clin Rehabil. 2015;29(12):1155-1167.

7. Mcshane CM, Macelhatton D. Desk Job - an app to encourage health and fitness in the workplace and beyond: mobile app user guide. $\mathrm{Br} J$ Sports Med. 2017;51(23):1705-1706.

8. Tunwattanapong P, Kongkasuwan R, Kuptniratsaikul V. The effectiveness of a neck and shoulder stretching exercise program among office workers with neck pain: a randomized controlled trial. Clin Rehabil. 2016;30(1):64-72.

9. van Eerd D, Munhall C, Irvin E, et al. Effectiveness of workplace interventions in the prevention of upper extremity musculoskeletal disorders and symptoms: an update of the evidence. Occup Environ Med. 2016;73(1):62-70.

10. Sveaas SH, Smedslund G, Hagen KB, Dagfinrud H. Effect of cardiorespiratory and strength exercises on disease activity in patients with inflammatory rheumatic diseases: a systematic review and metaanalysis. Br J Sports Med. 2017;51(14):1065-1072.

11. Pender NJ, Murdaugh CL, Parsons MA. Health promotion in nursing practice. 8th ed. Pearson Prentice: hall; 2019.

12. Morowatisharifabad MA, Ghofranipour F, Heidarnia A, Ruchi GB, Ehrampoush MH. Self-efficacy and health promotion behaviors of older adults in Iran. Social Behavior and Personality: An International Journal. 2006;34(7):759-768.

13. Delshad M, Tavafian S, Kazemnejad A. Factors predicting the stretching exercise behaviors of the office employees working in the Shahid Beheshti University of Medical Sciences in Tehran, Iran. Rev Inves Clin. In press 2019.

14. Delshad M, Tavafian S, Kazemnejad A. Design and Evaluation of Educational Programs based on Behavioral Change Model Developed Pender Stretching Exercises to Reduce Muscle Pain Skeletal Office Employers Shahid Beheshti University of Medical Sciences: Using the Three chapter Thesis Presented for the Degree of Doctor of Philosophy (Ph.D.) In Health Education and Health Promotion; Tarbiat Modares University of Iran, 2019.

15. Walker TJ, Tullar JM, Diamond PM, Kohl HW, Amick BC. Association of self-reported aerobic physical activity, muscle-strengthening physical activity, and stretching behavior with presenteeism. J Occup Environ Med. 2017;59(5):474-479.

16. Breivik H, Borchgrevink PC, Allen SM, et al. Assessment of pain. $\mathrm{Br}$ JAnaesth. 2008;101(1):17-24.

17. Mousavi SJ, Hadian MR, Abedi M, Montazeri A. Translation and validation study of the Persian version of the Western Ontario Rotator Cuff Index. Clin Rheumatol. 2009;28(3):293-299.

18. Naghdi S, Nakhostin Ansari N, Ashrafi H, Entezary E, Nakhostin Ansari A, Olyaei G. Cross-Cultural adaptation of the Micheli functional scale to Persian language for evaluation of low back pain in the young Athletes. Asian J Sports Med. 2015;6(4):26839.

19. Close MA, Lytle LA, Viera AJ, Chen D-G, Linnan LA, Valle CG. Identifying and describing segments of office workers by activity patterns: associations with demographic characteristics and objectively measured physical activity. Int J Workplace Health Manag. 2018;11(1):16-30.
20. Robertson MM, Huang YH, Lee J. Improvements in musculoskeletal health and computing behaviors: effects of a macroergonomics office workplace and training intervention. Appl Ergon. 2017;62: 182-196.

21. Lee H, Chae D, Cho S, Kim J, Yoo R. Influence of a community-based stretching intervention on the health outcomes among Korean-Chinese female migrant workers in South Korea: a randomized prospective trial. Jpn J Nurs Sci. 2017;14(4):277-287.

22. Cheng ST, Chan KL, Lam RWL, et al. A multicomponent intervention for the management of chronic pain in older adults: study protocol for a randomized controlled trial. Trials. 2017;18(1):528.

23. van Hoof W, O'Sullivan K, O'Keeffe M, Verschueren S, O'Sullivan P, Dankaerts W. The efficacy of interventions for low back pain in nurses: a systematic review. Int J Nurs Stud. 2018;77:222-231.

24. Ghazi C, Nyland J, Whaley R, Rogers T, Wera J, Henzman C. Social cognitive or learning theory use to improve self-efficacy in musculoskeletal rehabilitation: a systematic review and meta-analysis. Physiother Theory Pract. 2018;34(7):1-10.

25. Gill AL. The Impact of Positive Behavior Interventions and Supports on Attendance Rates and Office Discipline Referrals at the Middle School Level. Liberty University: Lynchburg, VA; 2017.

26. Stenberg U, Vågan A, Flink M, et al. Health economic evaluations of patient education interventions a scoping review of the literature. Patient Educ Couns. 2018;101(6):1006-1035.

27. Roebuck DD. Health Promotion LifestyleI Profile Of Low Income. Thesis Presented for the Degree of Doctor of Philosophy (Ph.D.) In Nursing Practice; Drexel University, 2017.

28. Niven A, Hu D. Office workers' beliefs about reducing sitting time at work: a belief elicitation study. Health Psychol Behav Med. 2018;6(1): 15-29.

29. Peterson CL, Evans KD, Axiotis IR. Sonographer scanning practices and musculoskeletal injury: evaluation of an occupational health issue using the health belief model. J Diagn Med Sonogr. 2017;33(5): $412-418$.

30. Such E, Mutrie N. Using organisational cultural theory to understand workplace interventions to reduce sedentary time. Int J Health Promot Educ. 2017;55(1):18-29.

31. Faisal M, Azizah Abdul R, Noorminshah AI. Managing Sedentary Behavior with Smartphone. Proceedings 253 of the 21th Pacific Asia Conference on Information Systems (PACIS); 2017 july 6-20; Langkawi, Island. Malaysia: 2017. Available from: http://aisel.aisnet.org/ pacis 2017/253.

32. Smith LE. Participation in Worksite Health Screening Activities, Health Behaviors, and Readiness to Change. [dissertation]. Mankato: Minnesota State University; 2017. Available from: https://cornerstone.lib. mnsu.edu/etds/687.

33. Laird Y, Fawkner S, Niven A. A grounded theory of how social support influences physical activity in adolescent girls. Int J Qual Stud Health Well-being. 2018;13(1):1435099.

34. Keegan JP, Chan F, Ditchman N, Chiu C-Y. Predictive ability of pender's health promotion model for physical activity and exercise in people with spinal cord injuries: a hierarchical regression analysis. Rehabil Couns Bull. 2012;56(1):34-47.

35. Archer KR, Coronado RA, Wegener ST. The role of psychologically informed physical therapy for musculoskeletal pain. Curr Phys Med Rehabil Rep. 2018;6(1):15-25.

36. Gibbs BB, Hergenroeder AL, Perdomo SJ, Kowalsky RJ, Delitto A, Jakicic JM. Reducing sedentary behaviour to decrease chronic low back pain: the stand back randomised trial. Occup Environ Med. 2018:oemed-2017-104732.

37. Irmak A, Bumin G, Irmak R. The effects of exercise reminder software program on office workers' perceived pain level, work performance and quality of life. Work. 2012;41 (Suppl 1):5692-5695.

38. Tavafian SS, Jamshidi AR, Mohammad K. Treatment of low back pain: randomized clinical trial comparing a multidisciplinary group-based rehabilitation program with oral drug treatment up to 12 months. Int J Rheum Dis. 2014;17(2):159-164. 
The Journal of Pain Research is an international, peer reviewed, open access, online journal that welcomes laboratory and clinical findings in the fields of pain research and the prevention and management of pain. Original research, reviews, symposium reports, hypothesis formation and commentaries are all considered for publication.

Submit your manuscript here: https://www.dovepress.com/journal-of-pain-research-journal

The manuscript management system is completely online and includes a very quick and fair peer-review system, which is all easy to use. Visit http://www.dovepress.com/testimonials.php to read real quotes from published authors. 